\title{
Fraction Unbound
}

National Cancer Institute

\section{Source}

National Cancer Institute. Fraction Unbound. NCI Thesaurus. Code C135490.

The ratio of free drug concentration to the total concentration. 